\title{
Modification of Surface Topography and Analysis of Its Impact on Friction and Wear Reduction of Sliding Contact
}

\author{
P. Venkateswara Babu, Syed Ismail, Satish Ben Beera
}

\begin{abstract}
Proper lubrication and surface modification are key factors to improve the tribological behavior of interacting sliding surfaces under lubricated conditions. Surface texturing of interacting surfaces has found to be an emerging technique that modifies the surfaces deterministically by producing surface features in the form of surface asperities or grooves with specific shape, size and distribution. The present paper address the impact of positive surface textures (protrusions) and number of positive textures in the sliding direction on friction and wear behavior of parallel sliding contacts. The square shaped positive surface textures are created on the specimen by ink-jet followed by chemical etching process. The sliding experiments are conducted on pin on disc friction and wear test rig by providing different sliding conditions such as plain dry, plain with lubricant and textures with lubricant between the interacting surfaces. The results indicated that the textures with lubricated condition exhibit lower friction and wear compared to other two conditions. Furthermore, it is reported that among the tested samples, the textured sample with number of textures three in sliding direction has shown a prominent effect in reducing friction and wear of parallel sliding contact.
\end{abstract}

Keywords: Friction coefficient; Parallel sliding contact; Surface modification; Surface texture; Wear rate

\section{INTRODUCTION}

Surface texturing is an effective way to enhance the tribological behavior of rubbing surfaces by modifying the surfaces in a specified manner [1-3]. This technique essentially alters the surface topography in a pre-determined way by producing the micro-features like dimples and grooves [4-6]. These surface features can be positive (protruded out of surface) or negative (recessed into the surface) [7]. Moreover, these micro-features can improve the lubrication conditions at the conjunction which further enhances the load support, frictional resistance and wear resistance of the rubbing pairs [8-11]. Under hydrodynamic or mixed lubrication, microfeatures act as "micro-wedges" to generate the hydrodynamic pressure by forming convergent clearances [12-13]. Under pure hydrodynamic lubrication, these micro-textures generate an additional hydrodynamic lift to separate the contact surfaces [14-16]. In starved lubrication conditions, these micro-textures acts as "micro-reservoirs" and supplies additional lubricant to the contact zone [17]. Furthermore, textures can also increase the anti-wear properties of the components by entrapping foreign particles/wear debris, which resulted in the prolonged life of the components [15, 18].

Surface texture can be applied to various mechanical components in order to get its advantageous effects. Several authors have been successfully used this technique to many engineering components which include mechanical seals, piston rings and journal bearings and others [19-21]. In the present paper, the influence of surface texturing, particularly positive textures (protrusions) were investigated on the tribological performance of the sliding contact. Square-shaped textures were fabricated on pin sample by the chemical etching process. The tribological performance was characterized by considering friction coefficient and specific wear rate. The sliding tests were conducted on the pin ondisc test rig under dry and lubricated conditions.

\section{MATERIALS AND METHODS}

The pin material selected for the experiments was AISI 1020 steel with a rectangular cross-section of $10 \mathrm{~mm} \times 3 \mathrm{~mm}$, and a length of $27 \mathrm{~mm}$. The disc was prepared of EN-31 steel with a $165 \mathrm{~mm}$ diameter and $8 \mathrm{~mm}$ thickness. The square-shaped textures with side length $500 \mu \mathrm{m}$ and height $70 \mu \mathrm{m}$ were produced on the pin sample by a chemical etching process. The detailed process can be found in the manuscript [7].

Revised Manuscript Received on December 02, 2019

* Correspondence Author

Syed Ismail*, Department of Mechanical Engineering, National Institute of Technology, Warangal, India. Email: syedismail7@nitw.ac.in

P. Venkateswara Babu, Department of Mechanical Engineering, National Institute of Technology, Warangal, India. Email: venky5041@ gmail.com

Satish Ben Beera, Department of Mechanical Engineering, National

Institute of Technology, Warangal, India. Email: satishben@nitw.ac.in 


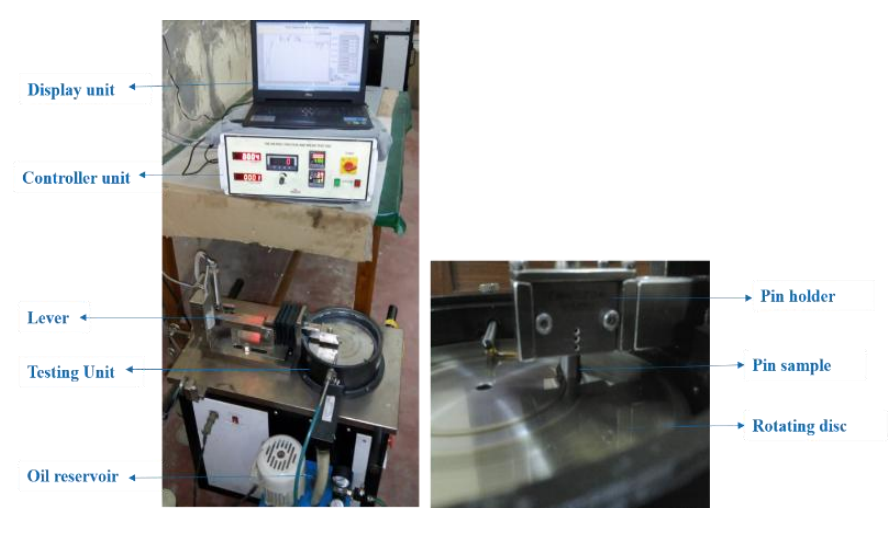

Fig.1. Schematic view of Pin on disc apparatus

The experiments were performed on a friction and wear test rig (pin on disc machine) by providing unidirectional sliding between a fixed pin and rotating disc. The test rig along with the contact mechanism is shown in Fig.1. It consists of a stationary pin on which the normal load applied and pressed against a rotating disc. The test rig mainly comprises of a testing unit, controller unit, and a display unit (see Fig. 1). The testing unit includes a lever to apply the load, pin holder to hold the pin firmly, LVDT sensors for friction force and wear measurement and an oil reservoir for the continuous supply of the lubricant. A second unit is a control unit which controls the speed of the motor. A third unit is a display unit, i.e., a computer which displays the readings of the friction force, friction coefficient, and wear.

\section{FRICTION COEFFICIENT AND WEAR RATE CALCULATIONS}

The pin on disc experiments was performed under dry and lubricated conditions. In the case of dry conditions, nontextured surface was considered while textured and nontextured specimens were considered for lubricated conditions. SAE15W-40 oil was selected to lubricate the sliding contact with a continuous supply of the oil at a rate of 20 drops per minute. The normal load was considered $30 \mathrm{~N}$ while the rotating speed of disc was kept at $400 \mathrm{rpm}$. The pin and disc samples were cleaned with acetone before starting each test to remove dirt particles and then dried. All the tests were conducted for 12 minutes at a track radius of $40 \mathrm{~mm}$. The weight of the sample was measured before and after each sliding test. After each test, the friction coefficient and specific wear rate were calculated by using equations (1) and (2). All the tests were conducted three times, and the mean values of friction coefficient and specific wear rate were calculated.

$$
\begin{aligned}
& \text { Friction coefficient }=\frac{F_{f}}{F_{n}} \\
& \text { Speific Wear rate }\left(\mathrm{mm}^{3} / \mathrm{Nm}\right)=\frac{\Delta W}{F_{n} \times \rho \times d_{s}}
\end{aligned}
$$

Where $F_{f}=$ friction force in $\mathrm{N}, F_{n}=$ normal load in $\mathrm{N}, \Delta W=$ weight loss of the ring sample in gm, $\rho=$ density of the pin sample in $\mathrm{gm} / \mathrm{mm}^{3}$ and $d_{s}=$ sliding distance in $\mathrm{m}$ which was calculated from $d_{s}=v \times t, v=$ sliding velocity in $\mathrm{m} / \mathrm{min}, t=$ sliding time in minutes.

\section{RESULTS AND DISCUSSION}

All the sliding experiments were performed on the pin on disc friction test rig at a room temperature of $30^{\circ} \mathrm{C}$. The experiments have been conducted on textured and non-textured surfaces under lubricated sliding conditions. However, in order to visualize the effect of a lubricated sliding condition, the results of dry sliding condition for plain surface were also included. After each test, the friction force, friction coefficient and specific wear rate were calculated by using Eqs. (1) \& (2). In the lubricated condition, the textured and non-textured pin samples were represented by $(\mathrm{T}+\mathrm{O})$ and $(\mathrm{O})$ respectively. In the case of textured samples, number of textures (n) in sliding direction was varied.

The results of the friction coefficient and specific wear rate were described in Fig 2. From Fig. 2(a), a drastic decrease in friction coefficient was identified under the lubricated condition as compared to the dry sliding state, which is obvious due to the presence of the lubricant. Under lubricated conditions, the textured pin sample exhibited more beneficial effects in reducing friction coefficient as compared to non-textured pin sample (see Fig.2 (a)). Because of additional hydrodynamic lift generated by textures between the interacting surfaces, due to which the sliding friction was reduced. However, textured sample with number of textures of three exhibited lowest friction coefficient among the textured samples.

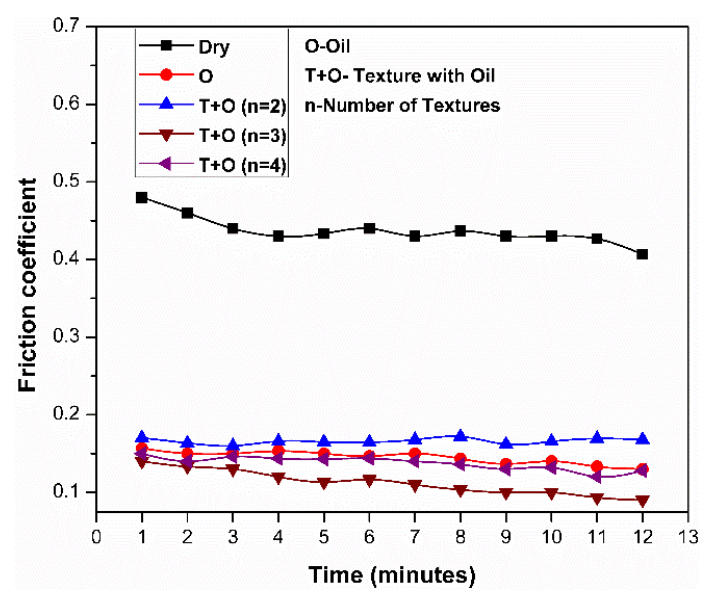

Fig.2 (a) Friction coefficient vs Time 


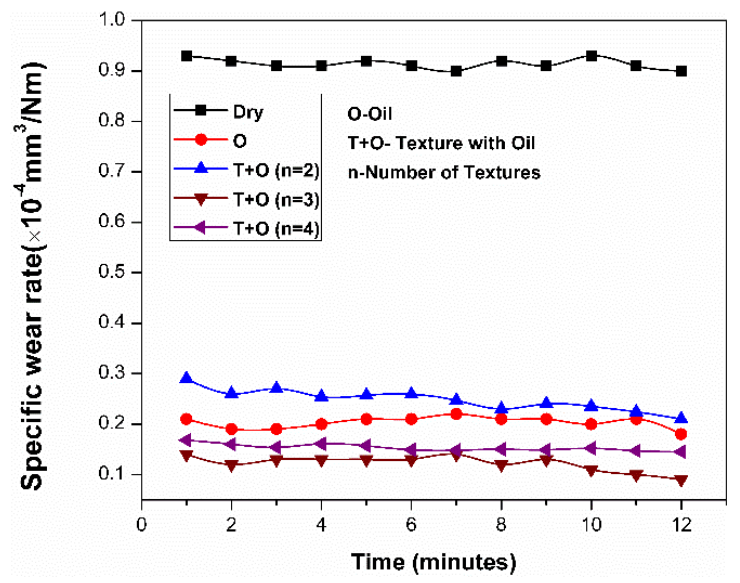

Fig.2 (b) Specific wear rate vs Time

Fig. 2(b) shows the results of specific wear rate under dry and lubricated sliding conditions. It was evident that the pin sample would experience severe wear and specific wear rate in dry condition when compared with lubricated sliding condition. Moreover, in the presence of the square-shaped textures along with the lubricated condition, a further reduction in wear rate was observed as compared to nontextured pin sample. This is probably due to the ability of surface texturing which offers a lower area of contact between the pin and disc samples and capturing the wear debris is the space between the textures, thus reduced the wear rate. Furthermore, the textured sample with number of textures of three reduced the specific wear rate more when compared with textured samples with number of textures of two and four in sliding direction.

Fig. 3 shows the mean friction coefficient and specific wear rate of textured and non-textured pin samples under lubricated conditions. The results confirmed that the textured pin samples significantly reduced the average friction coefficient and specific wear rate as compared to the nontextured case (see Fig. 3(a) \& 3(b)). Moreover, the maximum reduction of $23.2 \%$ and $38 \%$ were found in the friction coefficient and specific wear rate respectively.

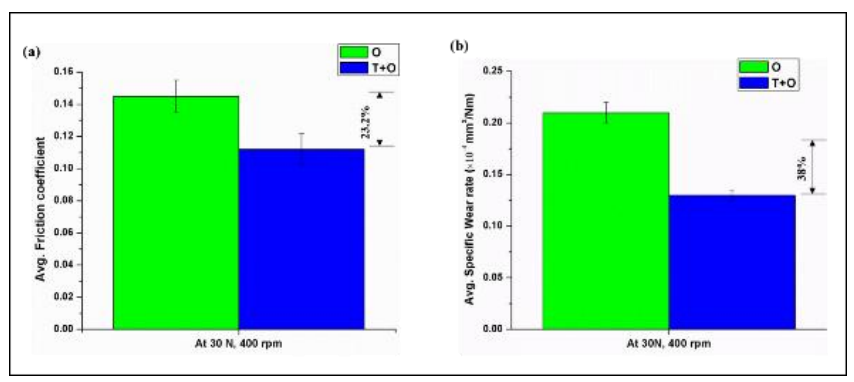

Fig.3. Average friction coefficient and Specific wear rate results

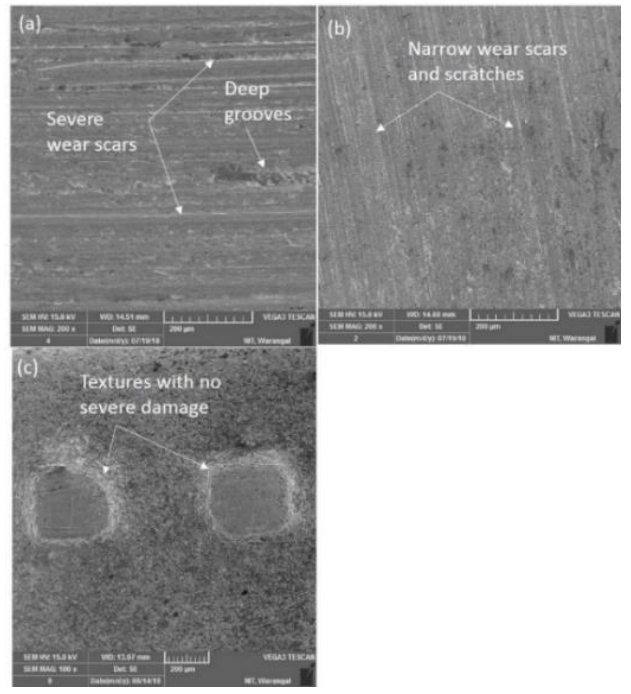

Fig. 4. Scanning Electron Micrographs of pin surface under (a) dry condition, (b) lubricated condition without textures (c) lubricated condition with textures

The Scanning electron micrographs of worn surfaces were depicted in Fig.4. It can be seen in Fig. 4 (a) that the deep grooves and the scratches were an indication of severe abrasive wear under dry condition. Similarly, the narrow wear scars from Fig. 4 (b) and 4 (c) would be evident for mild abrasive wear in the case lubricated conditions. Moreover, it was observed from Fig. 4 (c) that the textures were not damaged severely and no further indication of severe wear tracks or deep grooves as compared to non-textured pin surface. Based on the worn surface analysis, it was confirmed that the textured surfaces (in particular with number of textures of three) would be recommended to get the improved tribological performance of the sliding contact.

\section{CONCLUSIONS}

The positive textures (protrusions) were created on the pin surface to study its impact on the tribological performance of the sliding contact. The square-shaped textures having a side length of $500 \mu \mathrm{m}$ and a height of $70 \mu \mathrm{m}$ were fabricated by the chemical etching process. The tribological sliding tests were performed between the fixed pin against rotating disc under dry and lubrication conditions. From the results, it can be concluded that the reduction in friction coefficient and specific wear rate were obtained under lubricated sliding conditions when compared with dry sliding conditions. Besides, the textured samples have shown a substantial improvement in friction coefficient and specific wear rate by generating an additional hydrodynamic lift at the conjunction which separated the lubricated sliding surfaces. The textured pin samples with number of textures of three reduced friction coefficient by $23.2 \%$ and specific wear rate by $38 \%$ when compared with non-textured reference case. 


\section{REFERENCES}

[1]Fowell, M.T., Medina, S., Olver, A.V., Spikes, H.A. and Pegg, I.G., 2012. Parametric study of texturing in convergent bearings. Tribology International, 52, pp.7-16.

[2]Ma, C., Duan, Y., Yu, B., Sun, J. and Tu, Q., 2017. The comprehensive effect of surface texture and roughness under hydrodynamic and mixed lubrication conditions. Proceedings of the Institution of Mechanical Engineers, Part J: Journal of Engineering Tribology, 231(10), pp.13071319.

[3]Sudeep, U., Tandon, N. and Pandey, R.K., 2015. Performance of lubricated rolling/sliding concentrated contacts with surface textures: a review. Journal of Tribology, 137(3), p.031501.

[4]ZumGahr, K.H., Wahl, R. and Wauthier, K., 2009. Experimental study of the effect of micro-texturing on oil lubricated ceramic/steel friction pairs. Wear, 267(5-8), pp.1241-1251.

[5]Wahl, R., Schneider, J. and Gumbsch, P., 2012. In situ observation of cavitation in crossed microchannels. Tribology International, 55, pp.8186.

[6]Wahl, R., Schneider, J. and Gumbsch, P., 2012. Influence of the real geometry of the protrusions in micro textured surfaces on frictional behaviour. Tribology letters, 47(3), pp.447-453.

[7] P., V., Syed, I. and Beera, S., 2019. Influence of positive texturing on friction and wear properties of piston ring-cylinder liner tribo pair under lubricated conditions. Industrial Lubrication and Tribology, 71 (4), pp. 515-524.

[8]Wakuda, M., Yamauchi, Y., Kanzaki, S. and Yasuda, Y., 2003. Effect of surface texturing on friction reduction between ceramic and steel materials under lubricated sliding contact. Wear, 254(3-4), pp.356-363.

[9]Borghi, A., Gualtieri, E., Marchetto, D., Moretti, L. and Valeri, S., 2008. Tribological effects of surface texturing on nitriding steel for highperformance engine applications. Wear, 265(7-8), pp.1046-1051.

[10]Gachot, C., Rosenkranz, A., Hsu, S.M. and Costa, H.L., 2017. A critical assessment of surface texturing for friction and wear improvement. Wear, 372, pp.21-41.

[11]Costa, H.L. and Hutchings, I.M., 2009. Effects of die surface patterning on lubrication in strip drawing. Journal of Materials Processing Technology, 209(3), pp.1175-1180.

[12] Blatter, A., Maillat, M., Pimenov, S.M., Shafeev, G.A., Simakin, A.V. and Loubnin, E.N., 1999. Lubricated sliding performance of laserpatterned sapphire. Wear, 232(2), pp.226-230.

[13] Křupka, I., Vrbka, M. and Hartl, M., 2008. Effect of surface texturing on mixed lubricated non-conformal contacts. Tribology International, 41(11), pp.1063-1073.

[14] Pettersson, U. and Jacobson, S., 2003. Influence of surface texture on boundary lubricated sliding contacts. Tribology International, 36(11), pp.857-864. Pettersson, U. and Jacobson, S., 2003. Influence of surface texture on boundary lubricated sliding contacts. Tribology International, 36(11), pp.857-864.

[15] Pettersson, U. and Jacobson, S., 2004. Friction and wear properties of micro textured DLC coated surfaces in boundary lubricated sliding. Tribology letters, 17(3), pp.553-559.

[16] ZumGahr, K.H., Mathieu, M. and Brylka, B., 2007. Friction control by surface engineering of ceramic sliding pairs in water. Wear, 263(7-12), pp.920-929.

[17]Vlădescu, S.C., Medina, S., Olver, A.V., Pegg, I.G. and Reddyhoff, T., 2016. Lubricant film thickness and friction force measurements in a laser surface textured reciprocating line contact simulating the piston ring-liner pairing. Tribology International, 98, pp.317-329.

[18]Zhang, H., Zhang, D.Y., Hua, M., Dong, G.N. and Chin, K.S., 2014. A study on the tribological behavior of surface texturing on babbitt alloy under mixed or starved lubrication. Tribology Letters, 56(2), pp.305315.

[19]Etsion, I. and Sher, E., 2009. Improving fuel efficiency with laser surface textured piston rings. Tribology International, 42(4), pp.542-547.

[20]Wan, Y. and Xiong, D.S., 2008. The effect of laser surface texturing on frictional performance of face seal. Journal of Materials Processing Technology, 197(1-3), pp.96-100.

[21]Wang, X., Kato, K., Adachi, K. and Aizawa, K., 2003. Loads carrying capacity map for the surface texture design of $\mathrm{SiC}$ thrust bearing sliding in water. Tribology International, 36(3), pp.189-197. 